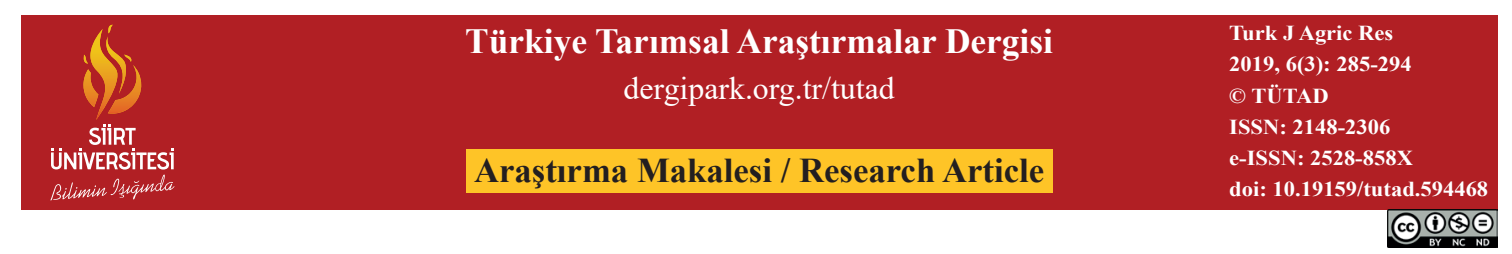

\title{
Mentha spicata L., Origanum onites L., Melissa officinalis L. ve Lavandula angustifolia Mill. Bitkilerinde Uçucu Yağ Oranı Üzerine Ontogenetik ve Diurnal Varyabilitenin Etkileri*
}

\author{
Gülen ÖZYAZICI ${ }^{1 * *}$, Kudret KEVSEROĞLU ${ }^{2}$ \\ ${ }^{I}$ Siirt Üniversitesi, Ziraat Fakültesi, Tarla Bitkileri Bölümü, Siirt, TÜRKIYYE \\ ${ }^{2}$ Ondokuz Mayls Üniversitesi, Ziraat Fakültesi, Tarla Bitkileri Bölümü, Samsun, TÜRKIYE
}

\begin{tabular}{ll}
\hline \multicolumn{1}{c}{ Geliş Tarihi/Received: 19.07 .2019} & Kabul Tarihi/Accepted: 12.11 .2019 \\
\hline ORCID ID (Yazar strasma göre / by author order) & \\
\hline (Dorcid.org/0000-0003-2187-6733 (Dorcid.org/0000-0002-9919-3396 & \\
"Sorumlu Yazar/Corresponding Author: gulenozyazici@sirt.edu.tr &
\end{tabular}

Öz: Bu çalışmada, Labiatae familyasına ait bazı bitkiler (Mentha spicata L., Origanum onites L., Melissa officinalis L. ve Lavandula angustifolia Mill.)'de ontogenetik ve diurnal varyabilitenin uçucu yağ oranı üzerine etkisinin araștırılması amaçlanmıştır. Araştırma, Türkiye'nin Orta Karadeniz Bölgesi’nde yer alan Bafra Ovası koşullarında iki yıl süre ile yürütülmüștür. Çalışmada, üç farklı hasat dönemi (Çiçeklenme öncesi, \% 50 çiçeklenme ve $\% 100$ çiçeklenme) ve üç farklı hasat saati [sabah $\left(07 .{ }^{00}\right)$, öğle $\left(13 . .^{30}\right)$ ve akşam $\left(19 .{ }^{00}\right)$ ] araştırma konusu olarak ele alınmıştır. Araştırma sonucuna göre uçucu yağ oranı değerleri, $M$. spicata, O. onites, L. angustifolia ve $M$. officinalis bitkilerinde sirasiyla \% 0.83-1.75, \% 1.50-2.67, $\%$ 0.25-1.33 ve \% 0.13-0.50 arasında değişiklik göstermiş olup; $M$. spicata ve $M$. officinalis' de \% 50, diğer bitkilerde ise tam çiçeklenme devrelerinde en yüksek değer ölçülmüştür. Hasat devreleri uçucu yağ oranını; M. spicata, ve L. angustifolia'da istatiksel olarak anlamlı derecede $(\mathrm{p}<0.01)$ etkilerken, $O$. onites ve $M$. officinalis türlerindeki etkileri istatistiksel açıdan önemsiz bulunmuştur. Hasat saatlerinin uçucu yağ oranı üzerine etkisi ise tüm bitkilerde önemli ve/veya çok önemli olmuştur. Araştırma sonucuna göre, ontogenetik varyabilite bakımından M. spicata ve M. officinalis bitkilerinin \% 50 çiçeklenme döneminde, $L$. angustifolia ve $O$. onites bitkilerinin ise $\% 100$ çiçeklenme döneminde hasat edilmesinin; diurnal varyabilite bakımından ise hasatların, $M$. spicata'da öğle, $O$. onites ve $M$. officinalis'te sabah, L. angustifolia' da ise akşam saatlerinde yapılmasının uygun olduğu önerilmiştir.

Anahtar Kelimeler: Hasat dönemleri, hasat saatleri, nane, İzmir kekiği, lavanta, oğulotu

\section{Effects of Ontogenetic and Diurnal Variability on Essential Oil Content in Mentha spicata L., Origanum onites L., Melissa officinalis L. and Lavandula angustifolia Mill.}

\begin{abstract}
The aim of this study was to investigate the effect of ontogenetic and diurnal variability on the essential oil content of some plants belonging to Labiatae family (Mentha spicata L., Origanum onites L., Melissa officinalis L. and Lavandula angustifolia Mill.). The study was conducted for two years at Bafra plain of Central Black Sea Region in Turkey. In this study, three different harvesting stages (before flowering, $50 \%$ flowering and $100 \%$ flowering) and harvesting times [morning $\left(07 .{ }^{00}\right.$, noon $\left(13 .^{30}\right)$, evening $\left(19.0^{00}\right)$ ] are considered as research subjects. According to the results of the study, the essential oil content values of $M$. spicata, $O$. onites, L. angustifolia and $M$. officinalis plants varied between $0.83-1.75 \%, 1.50-2.67 \%, 0.25-1.33 \%$ and $0.13-0.50 \%$, respectively; In M. spicata and M. officinalis, the highest value was measured at $50 \%$ flowering, while the highest values was measured at full flowering on other species. Harvesting stages significantly affected essential oil content in M. spicata and L. angustifolia $(\mathrm{p}<0.01)$, whereas the effects on $O$. onites and M. officinalis species were not significant. The effect of harvesting times on essential oil content was significant and /or very significant in all plants. According to results of the research, in terms of ontogenetic variability, it is recommended that M. spicata and M. officinalis plants should be harvested at 50\% flowering period, and L. angustifolia and O. onites plants should be harvested at $100 \%$ flowering period. In
\end{abstract}

\footnotetext{
": Bu çalışma; Ondokuz Mayıs Üniversitesi, Fen Bilimleri Enstitüsü tarafından kabul edilen birinci yazara ait "Ontogenetik ve Diurnal Varyabilitenin Labiatae Familyasına Ait Bazı Bitkilerin (Mentha spicata L., Origanum onites L., Lavandula angustifolia Mill., Melissa officinalis L.) Verim ve Baz Kalite Özelliklerine Etkisi” isimli Doktora Tez çalıșmasının bir bölümünden üretilmiștir.
} 
terms of diurnal variability, it was suggested that harvests should be done at noon in M. spicata, morning in $O$. onites and $M$. officinalis, and evening in L. angustifolia.

Keywords: Harvesting stages, harvesting times, mint, oregano, lavander, lemon balm

\section{Giriş}

Labiatae (Ballıbabagiller) familyası bitkileri; çoğunlukla ot ve çalı formunda, tek yıllık veya çok yıllık aromatik bitkiler olup, çok eski devirlerden beri tıbbi bitki olarak bilinen ve çoğunluğu Akdeniz Havzası'nda yayılış gösteren çok sayıda türe (yaklaşık 220 cinsi ve 3500 tür) sahiptir. Türkiye'de ise 38 cins, 400 tür yetişmekte ve bu türlerin 240'1 endemiktir. Labiatae familyasının uçucu yağ verimi oldukça yüksek olup, uçucu yağ verimi ve oranı bakımından Thymus, Origanum, Salvia, Mentha, Satureja, Teucrium, Melissa, Sideritis bilinen önemli cinsleri arasındadır (Erdoğan, 2014; Ulcay ve Şenel, 2018).

Sekonder metabolitler, bitkiler tarafindan üretilen ve günümüzde birçok sektörde hammadde olarak kullanılan, buna karşılık bitkinin yaşamsal işlevleri ile doğrudan ilişkili primer metabolitler (protein, yă̆, karbonhidrat) kadar önemli olan kimyasal maddelerdir. Geçmişte bitkiler tarafından atık madde olarak üretildikleri varsayılan sekonder metabolitlerin önemi 19. yüzyılda anlaşılmış ve bu konuda çalışmalar ağırlık kazanmıştır.

Çok çeşitli çevresel stresler (yüksek ve düşük sıcaklık, kuraklık, alkalilik, tuzluluk, ultraviyole stresi ve patojen enfeksiyonu) bitkilere potansiyel olarak zararlıdır. Bitkiler de bu olumsuz koşullardan korunmak için sekonder metabolitleri üretirler (Ramakrishna ve Ravishankar, 2011, Stevovic ve ark., 2011). Çeşitli stres koşulları altında (elverişsiz jeolojik, pedolojik, iklimsel veya biyotik koşullar), uçucu yağlarca zengin bitki sayısında artış olmaktadır. Sekonder metabolitlerin en önemlilerinden biri olan uçucu yağlar, tedavi edici özellikleri, antioksidan ve antimikrobiyal aktiviteleri nedeniyle ilaç, g1da ve parfüm endüstrisinin en önemli hammaddeleridir (Bayaz, 2014; Uçar ve ark., 2015). Ayrica biyolojik aktivitelerinden dolayı herbisit ve insektisit olarak kullanılmaktadırlar (Özen ve ark., 2017).

Tıbbi ve aromatik bitkiler, içerdikleri sekonder metabolitler nedeniyle üretilen bitkilerdir. Nane (Mentha spicata L.), İzmir kekiği (Origanum onites L.), oğulotu (Melissa officinalis L.) ve lavanta (Lavandula angustifolia Mill.) bitkilerinin yaprakları, çiçekleri ve uçucu yağları, ilaç, gıda, kozmetik ve parfümeri sanayiinde kullanılmaktadır. Tıbbi ve aromatik bitkilerde yapılan çalışmalarda; uçucu yağ oranları bitkinin genetik yapısına (Kokkini, 1992; Tuğay ve ark., 2000; Hadiana ve ark., 2008; Shanjani ve ark., 2010), yetiştiği iklim koşullarına (Piccaglia ve ark., 1993; Ceylan, 1997; Telci ve ark., 2010, Stevovic ve ark., 2011), tarımsal uygulamalara (Munsi, 1992; Court ve ark., 1993; Alkire ve Simon, 1996; Başyiğit ve Baydar, 2017) göre değiştikleri belirlenmiştir. $\mathrm{Bu}$ nedenle sekonder metabolitlerin değişiminin bilinmesi ve buna göre hasat zamanına karar verilmesi gerekir. Bu çalışmanın amacı; nane, İzmir kekiği, lavanta ve oğulotu bitkilerinin, uçucu yağ oranı üzerine etkili olan en uygun hasat dönemi ve saatinin belirlenmesidir.

\section{Materyal ve Yöntem}

Araştırma; 2002-2003 yıllarında, Türkiye'nin Orta Karadeniz Bölgesi'nde yer alan Bafra Ovası koşullarında yürütülmüştür. Araştırma topraklarının bazı fiziksel ve kimyasal özellikleri Tablo 1'de verilmiştir. Tablo 1'den de görüleceği üzere; araştırma yeri toprakları killi tekstürlü ve hafif alkali karakterde olup, toprakların tuzluluk problemi bulunmamaktadır. Araştırma topraklarının; organik madde içeriği iyi, kireç içeriği düşük, alınabilir fosfor kapsamı az ve alınabilir potasyum miktarı ise yüksek düzeydedir (Tablo 1).

Tablo 1. Araştırma yeri toprağının bazı fizikokimyasal özellikleri

\begin{tabular}{lc}
\hline Özellik & Değeri \\
\hline Kil, \% & 56.28 \\
Silt, \% & 36.15 \\
Kum, \% & 7.57 \\
pH & 7.85 \\
Elektriksel iletkenlik (EC), dS m & -1 \\
Kireç $\left(\mathrm{CaCO}_{3}\right), \%$ & 0.06 \\
Organik madde, \% & 5.3 \\
Alınabilir fosfor, $\mathrm{kg} \mathrm{P}_{2} \mathrm{O}_{5} \mathrm{da}^{-1}$ & 3.29 \\
Alınabilir potasyum, $\mathrm{kg} \mathrm{K}_{2} \mathrm{O} \mathrm{da}^{-1}$ & 5.97 \\
\hline
\end{tabular}

Samsun ili iklim verileri incelendiğinde; araştırma yılları sıcaklık ortalaması 14.2-14.9 ${ }^{\circ} \mathrm{C}$ arasında değişmiştir. Araştırmanın ilk yılında en düşük sıcaklık $4.5^{\circ} \mathrm{C}$ ile Ocak, ikinci yılında ise 4.8 ${ }^{\circ} \mathrm{C}$ ile Şubat aylarında, en yüksek sıcaklığın ise 2002 ve 2003 yıllarında sirasiyla Temmuz $\left(25.6^{\circ} \mathrm{C}\right)$ ve Ağustos $\quad\left(24.1 \quad{ }^{\circ} \mathrm{C}\right)$ aylarında ölçüldüğü görülmektedir. Araştırma yıllarında yıllık toplam yağış miktarı 573.3-779.7 mm olarak ölçülmüştür (Tablo 2) (Anonim, 2004).

Araştırmada; Bafra Ovası'nda yetiştiriciliği yapılan M. spicata türüne ait stolonlar, Ege 
Tablo 2. Samsun ili uzun yıllar (1974-2003) ve araştırma yıllarına ait bazı iklim değerleri

\begin{tabular}{|c|c|c|c|c|c|c|c|c|c|}
\hline \multirow{2}{*}{ Aylar } & \multicolumn{3}{|c|}{ Nispi nem (\%) } & \multicolumn{3}{|c|}{ Ortalama sicaklık $\left({ }^{\circ} \mathrm{C}\right)$} & \multicolumn{3}{|c|}{ Toplam yağ1ş (mm) } \\
\hline & 2002 & 2003 & UYO & 2002 & 2003 & UYO & 2002 & 2003 & UYO \\
\hline Ocak & 67.9 & 72.2 & 67.8 & 4.5 & 9.3 & 6.9 & 105.4 & 28.1 & 59.3 \\
\hline Şubat & 69.0 & 74.0 & 70.2 & 8.7 & 4.8 & 6.6 & 35.2 & 77.8 & 48.6 \\
\hline Mart & 72.1 & 75.4 & 75.8 & 9.8 & 5.0 & 7.8 & 34.1 & 73.5 & 53.2 \\
\hline Nisan & 79.8 & 79.6 & 79.5 & 10.2 & 8.7 & 11.1 & 61.9 & 45.0 & 58.3 \\
\hline May1s & 74.2 & 78.4 & 80.6 & 15.8 & 16.2 & 15.3 & 10.9 & 54.7 & 50.6 \\
\hline Haziran & 74.4 & 68.8 & 76.3 & 20.8 & 20.7 & 20.0 & 53.8 & 3.3 & 47.9 \\
\hline Temmuz & 73.5 & 72.5 & 73.4 & 25.6 & 23.7 & 23.1 & 79.9 & 37.2 & 31.3 \\
\hline Ağustos & 73.3 & 72.9 & 73.7 & 23.6 & 24.1 & 23.2 & 14.3 & 3.4 & 31.5 \\
\hline Eylül & 74.7 & 75.5 & 74.7 & 21.5 & 19.5 & 19.8 & 34.6 & 94.0 & 50.9 \\
\hline Ekim & 71.3 & 69.3 & 75.8 & 17.3 & 17.5 & 15.9 & 42.2 & 194.7 & 87.4 \\
\hline Kasim & 65.9 & 79.7 & 70.7 & 14.1 & 11.5 & 11.9 & 29.7 & 64.0 & 78.1 \\
\hline Aralık & 57.2 & 64.6 & 66.7 & 6.6 & 9.3 & 8.9 & 71.3 & 104.0 & 74.4 \\
\hline Toplam/Ortalama & 71.1 & 73.6 & 73.8 & 14.9 & 14.2 & 14.2 & 573.3 & 779.7 & 671.3 \\
\hline
\end{tabular}

Tarımsal Araştırma Enstitüsü'nden temin edilen $O$. onites L. tohumu, İsrail orijinli L. angustifolia Mill. tohumu ve İsveç'ten temin edilip (Mülga) Tokat Köy Hizmetleri Araştırma Enstitüsü’nde çoğaltılan $M$. officinalis L. tohumları bitkisel materyal olarak kullanılmıştır.

Araştırmada, Labiatae familyasına ait 4 bitki türünde ontogenetik (hasat dönemi: çiçeklenmeden hemen önceki devre-tomurcuklanmanın başlangıcı, $\% 50$ çiçeklenme devresi ve \% 100 çiçeklenme devresi-tam çiçeklenme) ve diurnal [günün üç farklı saati: sabah $\left(07 .{ }^{00}\right)$, öğle $\left(13 .{ }^{30}\right)$ ve akşam $\left(19 .{ }^{00}\right)$ ] varyabilite araştırma konusu olarak ele alınmış ve bitki hasatları belirtilen bu dönemlerde yapılmıştır.

Çalışmada tarla denemesi tesadüf blokları deneme desenine göre 3 tekerrürlü ve çakılı deneme şeklinde her bitki için ayrı ayrı kurulmuştur. Ön bitki hasadından sonra dikime hazır hale getirilen toprağa; dikimden bir ay önce, her parsele eşit olacak şekilde dekara 2 ton hesabıyla ahır gübresi verilmiş ve tarla dikime hazır hale getirilmiştir. Araştırmada, 3 × $2 \mathrm{~m}$ boyutlarındaki parsellere 50 $\mathrm{cm}$ sira aralığında olmak üzere; nanede $30 \mathrm{~cm}$, İzmir kekiği ve oğulotunda $20 \mathrm{~cm}$, lavantada ise 40 $\mathrm{cm}$ sıra üzeri mesafe uygulanmıştır. Nane stolonları doğrudan tarlaya, diğer bitkilerin ise tohumundan elde edilen fideleri tarlaya dikilmiştir. Buna göre, nane ve İzmir kekiğinde 27.05.2002 tarihinde, lavanta ve oğulotu bitkilerinde ise 29.05.2002 tarihinde dikimler gerçekleştirilmiştir. Her parsele $10 \mathrm{~kg} \mathrm{da}^{-1}$ saf azot (N) hesabiyla azotlu gübrenin (amonyum sülfat, \% $21 \mathrm{~N}$ ) yarısı dikimle birlikte, kalan diğer yarısı birinci biçimlerden sonra uygulanmıştır. Fosforlu gübre (triple süper fosfat, $\%$ 43-44 $\mathrm{P}_{2} \mathrm{O}_{5}$ ) ise dekara $5 \mathrm{~kg}$ saf $\mathrm{P}_{2} \mathrm{O}_{5}$ olacak şekilde tamamı dikim sırasında verilmiştir.

Biçimi yapılan parsellerden elde edilen taze herbaların yaprakları (lavantada çiçekleri) ayrılarak oda sıcaklığında kurutulmuştur. Kurutulmuş yaprak ve çiçeklerden (lavanta için) alınan örneklerin uçucu yă̆ oranları su distilasyonu yöntemiyle belirlenmiştir. Uçucu yağların distilasyonu için ayıklanmış ve kurutulmuş $100 \mathrm{~g}$ yaprak/çiçek örnekleri 2000 ml'lik balonlara yerleştirildikten sonra $1000 \mathrm{ml}$ saf su eklenerek 3 saat boyunca distilasyon işlemi gerçekleştirilmiştir. Distilasyon işlemi tamamlandıktan sonra Neo-Clevenger aparatının dereceli kısmından uçucu yağların miktarı ml olarak okunarak yüzde (\%) oranları (v/w) belirlenmiştir.

Elde edilen verilerde y1llar ayrı ayrı varyans analizine tabi tutulmuştur. Nane bitkisinde her iki yılda da biçim sayıları aynı olduğu için tesadüf bloklarında bölünen bölünmüş parseller deneme desenine göre, diğer bitkilerde biçim sayıları eşit olmadığ 1 için birinci yıl tesadüf bloklarında bölünmüş parseller, ikinci y1l değerleri ise tesadüf bloklarında bölünen bölünmüş parseller deneme desenine göre varyans analizi yapılarak sonuçlar değerlendirilmiştir. Ortalamalar arasındaki farklılıklar Duncan çoklu karşılaştırma testine göre gruplandırılmıştır (Yurtsever, 1984).

\section{Bulgular ve Tartışma}

\subsection{Nane (Mentha spicata L.) bitkisinin uçucu yağ oranı üzerine ontogenetik ve diurnal varyabilitenin etkisi}

Araştırmanın her iki yılında nane bitkisinde iki biçim yapılmış olup, değerler iki biçimin sonucu olarak verilmiştir. Farklı hasat dönemlerinde (HD), farklı biçim sırasında (BS) ve hasat saatlerinin (HS) nane bitkisine uçucu yağ oranı değerleri Tablo 3 'te verilmiştir. Araştırmanın ilk yılında, uçucu yağ oranı üzerine hasat dönemlerinin etkisi önemsiz olurken, ikinci yılda ise istatistiki açıdan $\mathrm{p}<0.01$ seviyesinde önemli olmuştur. Araştırmanın ikinci yılında, en yüksek uçucu yăg oranı çiçeklenme öncesi ve tam çiçeklenme döneminde hasat edilen 
Tablo 3. Nane (M. spicata L.) bitkisinde farklı hasat dönemi ve hasat saatlerinde elde edilen uçucu yağ oranları $(\%)^{1}$

\begin{tabular}{|c|c|c|c|c|c|}
\hline \multirow{2}{*}{ Yillar } & \multirow{2}{*}{ Hasat dönemi } & \multirow{2}{*}{ Hasat saatleri } & \multicolumn{2}{|c|}{ Biçim sıraları } & \multirow{2}{*}{$\begin{array}{c}\text { HDxHS } \\
\text { interaksiyonu }\end{array}$} \\
\hline & & & 1. biçim & 2. biçim & \\
\hline \multirow{16}{*}{2002} & \multirow{4}{*}{ Çiçeklenme öncesi } & Sabah & 1.13 & 1.30 & $1.22 \mathrm{bcd}$ \\
\hline & & Öğle & 1.33 & 1.50 & $1.42 \mathrm{ab}$ \\
\hline & & Akşam & 1.17 & 1.33 & $1.25 \mathrm{bc}$ \\
\hline & & Ortalama & 1.21 & 1.38 & 1.29 \\
\hline & \multirow{4}{*}{ \% 50 çiçeklenme } & Sabah & 1.00 & 0.67 & $0.83 \mathrm{~d}$ \\
\hline & & Öğle & 1.83 & 1.67 & $1.75 \mathrm{a}$ \\
\hline & & Akşam & 1.33 & 0.83 & $1.08 \mathrm{~cd}$ \\
\hline & & Ortalama & 1.39 & 1.06 & 1.22 \\
\hline & \multirow{4}{*}{ \% 100 çiçeklenme } & Sabah & 1.33 & 0.92 & $1.13 \mathrm{bcd}$ \\
\hline & & Öğle & 1.50 & 1.50 & $1.50 \mathrm{ab}$ \\
\hline & & Akşam & 1.00 & 0.67 & $0.83 \mathrm{~d}$ \\
\hline & & Ortalama & 1.28 & 1.03 & 1.15 \\
\hline & \multicolumn{2}{|l|}{ Genel ortalama (BS) } & 1.29 & 1.15 & \\
\hline & \multirow{3}{*}{ Genel ortalama (HS) } & Sabah & $1.06 \mathrm{~b}$ & & \\
\hline & & Öğle & $1.56 \mathrm{a}$ & & \\
\hline & & Akşam & $1.05 \mathrm{~b}$ & & \\
\hline \multirow{16}{*}{2003} & \multirow{4}{*}{ Çiçeklenme öncesi } & Sabah & 1.50 & 1.00 & $1.25 \mathrm{~d}$ \\
\hline & & Öğle & 2.00 & 2.00 & $2.00 \mathrm{a}$ \\
\hline & & Akşam & 1.33 & 1.33 & $1.33 \mathrm{~cd}$ \\
\hline & & Ortalama & $1.61 \mathrm{a}$ & $1.44 \mathrm{a}$ & $1.53 \mathrm{~A}$ \\
\hline & \multirow{4}{*}{ \% 50 çiçeklenme } & Sabah & 1.00 & 1.33 & $1.17 \mathrm{de}$ \\
\hline & & Öğle & 1.50 & 2.00 & $1.75 \mathrm{~b}$ \\
\hline & & Akşam & 0.83 & 1.17 & $1.00 \mathrm{e}$ \\
\hline & & Ortalama & $1.11 \mathrm{~b}$ & $1.50 \mathrm{a}$ & $1.31 \mathrm{~B}$ \\
\hline & \multirow{4}{*}{ \% 100 çiçeklenme } & Sabah & 1.00 & 1.00 & $1.00 \mathrm{e}$ \\
\hline & & Öğle & 2.00 & 2.00 & $2.00 \mathrm{a}$ \\
\hline & & Akşam & 1.50 & 1.50 & $1.50 \mathrm{c}$ \\
\hline & & Ortalama & $1.50 \mathrm{a}$ & $1.50 \mathrm{a}$ & $1.50 \mathrm{~A}$ \\
\hline & \multicolumn{2}{|l|}{ Genel ortalama (BS) } & 1.41 & 1.48 & \\
\hline & \multirow{3}{*}{ Genel ortalama (HS) } & Sabah & $1.14 \mathrm{c}$ & & \\
\hline & & Öğle & $1.92 \mathrm{a}$ & & \\
\hline & & Akşam & $1.28 \mathrm{~b}$ & & \\
\hline $\mathrm{LSD}_{0.05}$ & \multicolumn{5}{|c|}{$\mathrm{HS}_{(2002)}=0.45^{* *}, \mathrm{HS}_{(2003)}=0.09^{* *}, \mathrm{HDxHS}_{(2002)}=0.47^{*}, \mathrm{HDxHS}_{(2003)}=0.17^{* *}, \mathrm{HDxBS}_{(2003)}=0.26^{* *}$} \\
\hline
\end{tabular}

${ }^{1}$ : Konulara göre ayrı ayrı olmak üzere, aynı harfle gösterilen ortalamalar arasındaki farklılık istatistiksel olarak önemsizdir, HD: Hasat dönemi, HS: Hasat saati, BS: Biçim sırası, ${ }^{*}: \mathrm{p}<0.05$ düzeyinde önemli farklılık, $* *: \mathrm{p}<0.01$ düzeyinde önemli farklılık

bitkilerde (sırasıyla $\% 1.53$ ve $\% \quad 1.50)$ tespit edilmiştir (Tablo 3).

Nane bitkisinde hasat saatlerinin etkisi her iki yılda da istatiksel açıdan $\mathrm{p}<0.01$ seviyesinde önemlilik göstermiştir. Her iki yılda da hasat dönemleri ile biçim sıralarının ortalaması olarak en yüksek uçucu yağ oranı değeri, öğle saatlerinde yapılan biçimlerde saptanmıştır (sırasıyla \% 1.56 ve $\%$ 1.92). Araştırmanın her iki yılında da biçim sıralarının uçucu yağ oranı üzerine etkisi önemsiz olmuştur. HDxHS interaksiyonunun nanenin uçucu yağ oranı üzerine etkisi ilk y1l $\mathrm{p}<0.05$, ikinci yıl ise $\mathrm{p}<0.01$ seviyesinde önemlilik göstermiştir (Tablo 3). Her iki yılda da en yüksek uçucu yağ oranları tüm hasat dönemlerinde öğle saatinde yapılan biçimlerde elde edilmiştir (Şekil 1 ve 2).

Nane bitkisinin farklı hasat dönemlerinde, günün farklı saatlerindeki hasatlarda ve farklı biçim sıralarına göre elde edilen uçucu yağ oranı üzerine
HDxBS interaksiyonunun etkisi ilk y1l istatiksel olarak önemsiz, ikinci yılda ise $p<0.01$ seviyesinde önemli bulunmuştur. En düşük uçucu yağ oranı $\% 1.11$ ile $\% 50$ çiçeklenme döneminin 1 . biçiminde belirlenmiş, diğer hasat dönemlerinde ve biçim sıralarında elde edilen uçucu yağ oranları istatistiki olarak aynı grupta yer almışlardır (Tablo 3 ve Şekil 3). Nane bitkisinin uçucu yağ oranı üzerine HSxBS ikili interaksiyonu ile HDxHSxBS üçlü interaksiyonunun etkileri her iki yılda da önemsiz bulunmuştur (Tablo 3).

Şengül (1990), Menemen ekolojik koşullarında M. piperita var. mitcham ve $M$. arvensis var. piperascens türlerinde en yüksek uçucu yă̆ oranının normal hasat olarak ifade ettiği çiçeklenme döneminde elde edildiğini; Özel (2000) ise çiçeklenme başlangıcı döneminde uçucu yă̆ oranının yüksek olduğunu, hasat zamanı geciktikçe uçucu yağ oranının azaldığını ifade etmişlerdir. 


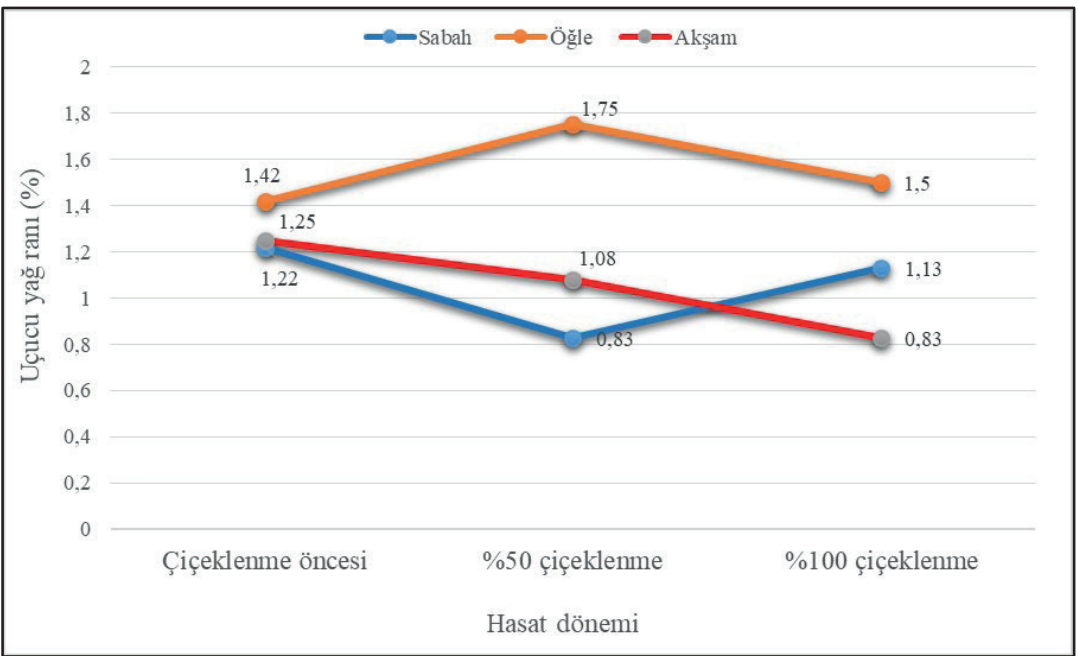

Şekil 1. M. spicata bitkisinde hasat dönemleri ve hasat saatlerine göre uçucu yağ oranının değişimi (2002 yılı)

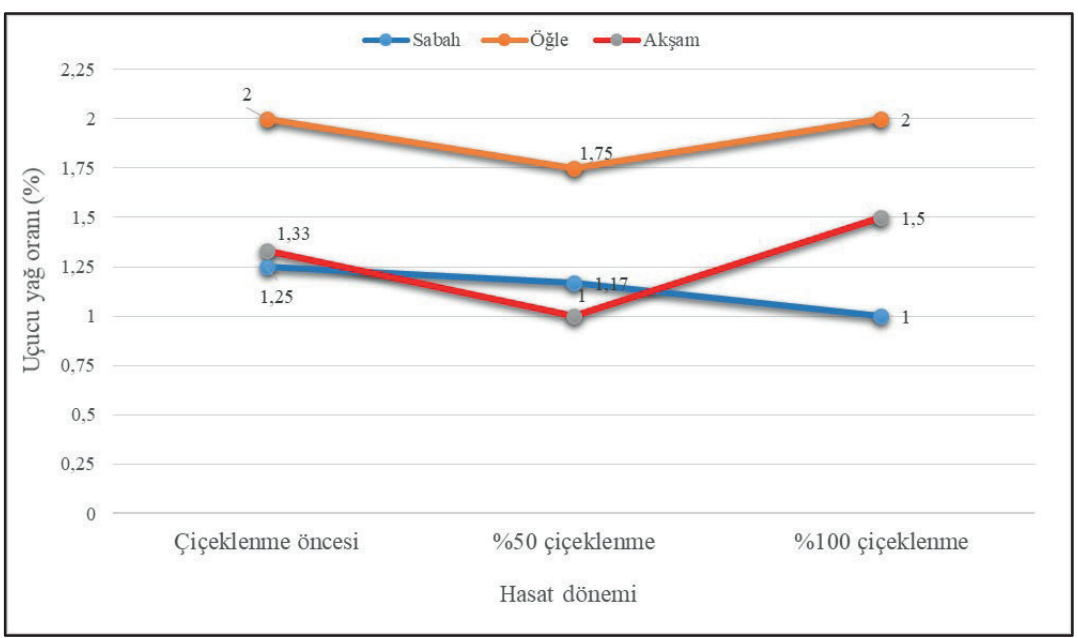

Şekil 2. M. spicata bitkisinde hasat dönemleri ve hasat saatlerine göre uçucu yă oranının değişimi (2003 yılı)

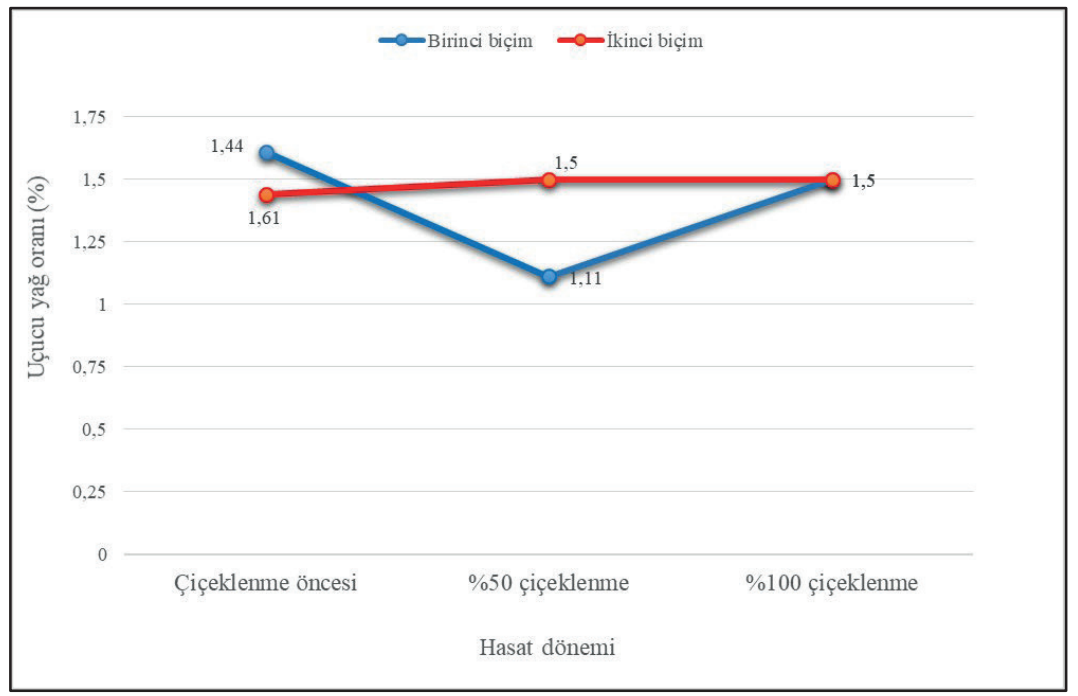

Şekil 3. $M$. spicata bitkisinde hasat dönemleri ve biçim sıralarına göre uçucu yağ oranının değişimi (2003 yılı) 
M. spicata ile yapılan çalışmada en yüksek uçucu yağ içeriğini Kızıl ve Toncer (2006) tam çiçeklenme döneminde (\% 2.63), M. arvensis'te Çalışkan ve Özgüven (2018) tarafından yapılan çalışmada ise en yüksek uçucu yağ oranının çiçeklenme döneminde (\% 7.69) elde edildiğini rapor etmişlerdir.

\section{2. İzmir kekiği (Origanum onites L.) bitkisinin uçucu yağ oranı üzerine ontogenetik ve diurnal varyabilitenin etkisi}

Farklı hasat dönemlerinin İzmir kekiği bitkisinin uçucu yağ oranına etkisi her iki yılda istatiksel olarak önemsiz bulunmuştur. Hasat dönemlerine göre uçucu yağ oranı araştırmanın ilk y1lında \% 2.17-2.46 arasında, ikinci y1l ise \% 1.782.00 arasında değişiklik göstermiştir (Tablo 4).
Araştırmanın ilk yılında hasat saatlerinin etkisi istatiksel olarak önemli görülmezken, ikinci yıl hasat saatlerinin ve biçim sırasının etkisi $\mathrm{p}<0.01$ düzeyinde önemli görülmüştür. Buna göre 2003 yılında hasat saatlerine göre en yüksek uçucu yağ oranı, \% 2.31 ile sabah saatlerinde, biçim sirasina göre ise \% 2.09 ile 2. biçimde saptanmıştır (Tablo 4).

Uçucu yağ oranı üzerine her iki araştırma yılında HDxHS interaksiyonu, 2003 yilinda ise HDxBS, HSxBS ikili interaksiyonları ile HDxHSxBS üçlü interaksiyonunun etkileri önemsiz bulunmuştur. HDxHS interaksiyonuna göre 2002 yılında uçucu yağ oranı \% 1.83-2.67, 2003 yılında ise \% 1.50-2.42 arasında değişiklik göstermiştir (Tablo 4).

Tablo 4. İzmir kekiği (O. onites L.) bitkisinde farklı hasat dönemi ve hasat saatlerinde elde edilen uçucu yağ oranları $(\%)^{1}$

\begin{tabular}{|c|c|c|c|c|c|}
\hline \multirow{2}{*}{ Yillar } & \multirow{2}{*}{ Hasat dönemi } & \multirow{2}{*}{ Hasat saatleri } & \multicolumn{2}{|c|}{ Biçim sıraları } & \multirow[t]{2}{*}{$\begin{array}{c}\text { HDxHS } \\
\text { interaksiyonu }\end{array}$} \\
\hline & & & 1. biçim & 2. biçim & \\
\hline \multirow{16}{*}{2002} & \multirow{4}{*}{ Çiçeklenme öncesi } & Sabah & 2.67 & --- & 2.67 \\
\hline & & Öğle & 2.37 & --- & 2.37 \\
\hline & & Akşam & 2.33 & --- & 2.33 \\
\hline & & Ortalama & 2.46 & --- & 2.46 \\
\hline & \multirow{4}{*}{ \% 50 çiçeklenme } & Sabah & 2.40 & --- & 2.40 \\
\hline & & Öğle & 2.33 & --- & 2.33 \\
\hline & & Akşam & 2.17 & --- & 2.17 \\
\hline & & Ortalama & 2.30 & --- & 2.30 \\
\hline & \multirow{4}{*}{ \% 100 çiçeklenme } & Sabah & 2.50 & --- & 2.50 \\
\hline & & Öğle & 2.17 & --- & 2.17 \\
\hline & & Akşam & 1.83 & --- & 1.83 \\
\hline & & Ortalama & 2.17 & --- & 2.17 \\
\hline & \multicolumn{2}{|l|}{ Genel ortalama (BS) } & 2.31 & & \\
\hline & \multirow{3}{*}{ Genel ortalama (HS) } & Sabah & 2.52 & & \\
\hline & & Öğle & 2.29 & & \\
\hline & & Akşam & 2.11 & & \\
\hline \multirow{16}{*}{2003} & \multirow{4}{*}{ Çiçeklenme öncesi } & Sabah & 2.50 & 2.33 & 2.42 \\
\hline & & Öğle & 1.83 & 2.00 & 1.92 \\
\hline & & Akşam & 1.33 & 2.00 & 1.67 \\
\hline & & Ortalama & 1.89 & 2.11 & 2.00 \\
\hline & \multirow{4}{*}{$\% 50$ çiçeklenme } & Sabah & 2.17 & 2.17 & 2.17 \\
\hline & & Öğle & 1.33 & 2.00 & 1.67 \\
\hline & & Akşam & 1.33 & 1.67 & 1.50 \\
\hline & & Ortalama & 1.61 & 1.94 & 1.78 \\
\hline & \multirow{4}{*}{ \% 100 çiçeklenme } & Sabah & 2.00 & 2.67 & 2.34 \\
\hline & & Öğle & 1.50 & 2.04 & 1.77 \\
\hline & & Akşam & 1.33 & 2.00 & 1.67 \\
\hline & & Ortalama & 1.61 & 2.23 & 1.92 \\
\hline & \multicolumn{2}{|l|}{ Genel ortalama (BS) } & $1.70 \mathrm{~b}$ & $2.09 \mathrm{a}$ & \\
\hline & \multirow{3}{*}{ Genel ortalama (HS) } & Sabah & $2.31 \mathrm{a}$ & & \\
\hline & & Öğle & $1.79 \mathrm{~b}$ & & \\
\hline & & Akşam & $1.61 \mathrm{~b}$ & & \\
\hline $\mathrm{LSD}_{0.05}$ & \multicolumn{2}{|c|}{$\mathrm{HS}_{(2003)}=0.30^{* *}, \mathrm{BS}_{(2003)}=0.23^{* *}$} & & & \\
\hline
\end{tabular}


İzmir kekiğinde yapılan çalışmalarda uçucu yağ oranının, \% 2.61-5.12 (Ceylan ve ark., 1999) ve \% 3.0-3.4 (Batıray ve Kan, 2013) arasında değişim gösterdiği rapor edilmiştir. Sağlam (2005), en yüksek uçucu yağ oranının \% 1.58 oranı ile $\% 50$ çiçeklenme döneminde ve sabah saatlerinde; Yaldız ve ark. (2005), en yüksek uçucu yağ oranının \% 1.62 ile çiçeklenme sonrasında; Kızıl ve ark. (2009), \% 3.65 ile tam çiçeklenme döneminde öğleden sonra yapılan hasatlarda; Sönmez (2019) ise \% 3.47-4.49 arasında değişen uçucu yağ oranının Mayıs, Haziran, Temmuz ve Eylül aylarında yapılan biçimlerden elde edildiğini bildirmişlerdir.

\subsection{Lavanta (Lavandula angustifolia Mill.) bitkisinin uçucu yă oranı üzerine ontogenetik ve diurnal varyabilitenin etkisi}

Lavanta bitkisinde ontogenetik ve diurnal varyabilitenin uçucu yağ oranı üzerine etkisi 2002 yılında incelenmiş, 2003 yılında diurnal varyabilite parsellerindeki bitkilerden uçucu yă analizine yetecek kadar çiçek miktarı elde edilememiş ve bu nedenle tek yıllık sonuçlar verilmiştir. Lavanta bitkisinde uçucu yağ oranı üzerine hasat dönemlerinin ve hasat saatlerinin etkisi istatiksel olarak $\mathrm{p}<0.01$ düzeyinde önemli bulunmuştur. Tek yıllık sonuçlara göre, lavanta bitkisinde, hasat saatlerinin ortalaması olarak en yüksek uçucu yağ oranı \% 0.86 ile \% 50 çiçeklenme devresinde hasat edilen çiçeklerde tespit edilmiştir. En yüksek uçucu yağ oranı akşam saatlerinde hasat edilen bitkilerde tespit edilmiştir (Tablo 5).

Lavanta bitkisinin uçucu yă̆ oranı üzerine HDxHS interaksiyonunun etkisi ise önemli $(p<0.05)$ çıkmıştır. Buna göre en yüksek uçucu yağ oranı \% 1.33 ile \% 50 çiçeklenme döneminde ve akşam saatinde yapılan hasatlarda elde edilmiştir (Tablo 5 ve Şekil 4).

Uçucu yağın miktar ve kalitesini bitkinin genetik yapısının etkili olduğu kadar iklim ve edafik faktörlerinde etkili olduğu araştırmacılar tarafından rapor edilmiştir (Chang ve ark., 2009; Shanjani ve ark., 2010; Başyiğit ve Baydar, 2017; Sönmez ve Okkaoğlu, 2019). Farklı ekolojik koşullarda yürütülen çalışmalarda uçucu yağ oranının; Arabacı ve Bayram (2005) \% 1.54-2.34, Kara (2011) $\%$ 2.10-2.30, Zheljazkov ve ark. (2012) \% 0.711.30, Balyemez (2014) \% 0.92-0.99, Arslancan (2016) \% 4.93-9.13, Karık ve ark. (2017) \% 1.303.05 ve Sönmez ve Okkaoğlu (2019) ise \% 2.684.40 arasında değişim gösterdiğini ifade etmişlerdir.

Tablo 5. Lavanta (L. angustifolia Mill.) bitkisinde farklı hasat dönemi ve hasat saatlerinde elde edilen uçucu yağ oranları $(\%)^{1}$

\begin{tabular}{llccc}
\hline \multirow{2}{*}{ Hasat dönemi } & \multicolumn{3}{c}{ Hasat saatleri } & \multirow{2}{*}{ Ortalama $^{* *}$} \\
\cline { 2 - 4 } & Sabah & Öğle & Akşam & $0.39 \mathrm{~B}$ \\
Çiçeklenme öncesi & $0.25 \mathrm{c}$ & $0.42 \mathrm{bc}$ & $0.50 \mathrm{bc}$ & $0.86 \mathrm{~A}$ \\
$\% 50$ çiçeklenme & $0.42 \mathrm{bc}$ & $0.83 \mathrm{~b}$ & $1.33 \mathrm{a}$ & $0.39 \mathrm{~B}$ \\
\% 100 çiçeklenme & $0.25 \mathrm{c}$ & $0.42 \mathrm{bc}$ & $0.50 \mathrm{bc}$ & $0.78 \mathrm{~A}$ \\
\hline Ortalama** & $0.31 \mathrm{C}$ & $0.56 \mathrm{~B}$ & 0.2
\end{tabular}

$\mathrm{LSD}_{0.05} \mathrm{HD}=0.274^{* *}, \mathrm{HS}=0.240^{* *}, \mathrm{HDxHS}=0.297^{*}$

1: Konulara göre ayrı ayrı olmak üzere, aynı harfle gösterilen ortalamalar arasındaki farklılık istatistiksel olarak önemsizdir, HD: Hasat dönemi, HS: Hasat saati, *: $\mathrm{p}<0.05$ düzeyinde önemli farkl1lık, $* *$ : $\mathrm{p}<0.01$ düzeyinde önemli farklılık

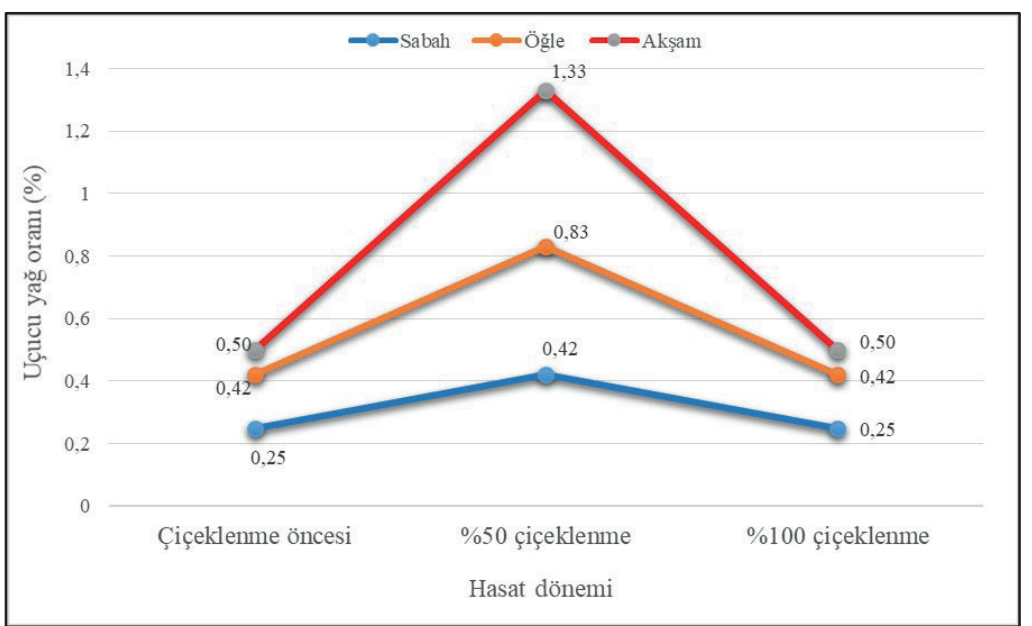

Şekil 4. L. angustifolia bitkisinde hasat dönemleri ve hasat saatlerine göre uçucu yă̆ oranının değişimi 


\subsection{Oğulotu (Melissa officinalis L.) bitkisinin uçucu yağ oranı üzerine ontogenetik ve diurnal varyabilitenin etkisi}

Oğulotu bitkisinde hasat dönemlerinin uçucu yağ oranı üzerine etkileri her iki yılda da istatistiki olarak önemli olmamakla beraber, her iki yılda da $\% 50$ çiçeklenme dönemine kadar artmış ve \% 100 çiçeklenme devresinde ise azalış eğilimi göstermiştir. Araştırmanın ilk yılında, hasat dönemlerine göre uçucu yağ oranı \% $0.24-0.31$ arasında, ikinci yılda ise \% $0.33-0.44$ arasında değişmiştir (Tablo 6).

Günün farklı saatlerinde yapılan hasatların uçucu yağ oranı üzerine etkileri ise her iki araştırma yılında da istatiksel olarak $\mathrm{p}<0.01$ seviyesinde önemlilik göstermiştir. Buna göre hasat dönemlerinin ortalaması olarak en yüksek uçucu yağ oranı 2002 ve 2003 yıllarında sabah saatlerinde yapilan hasatlarda (sırasiyla, \% 0.39 ve \% 0.50 ) belirlenmiştir. Uçucu yağ oranı üzerine HDxHS interaksiyonu önemsiz bulunmuştur. İlk y1l uçucu yağ oran $1 \% 0.10-0.42$, ikinci y1l ise \% $0.25-0.50$ arasında değişmiştir (Tablo 6).

Oğulotu bitkisi ile yapılan araştırmalarda, uçucu yağ oranının \% $0.004-\% 0.158$ arasında değişim gösterdiği bildirilmiştir (Sar1 ve Ceylan, 2002; Arslan, 2006; Telli, 2007; Kaçar ve ark., 2010; Özyiğit ve ark., 2016). En yüksek uçucu yağ oranını Arabac1 (1989), \% 0.33 ile tam çiçeklenme döneminde; Tinmaz (1999), çiçeklenme başlangıcında (\% 0.14); Sağlam (2005), \% 100 çiçeklenme döneminde ve sabah saatlerinde (\% 0.46); Kizıl (2009), \% 0.093 oranı ile tam çiçeklenme döneminde; Uyanık (2013), drog yaprak ve drog herbada çiçeklenme öncesi dönemde (sirasılya, \% 0.13 ve $\% 0.08$ ) ve saat 12.00 'de (sırasiyla, \% 0.08 ve \% 0.08); Avci ve Akcali Giachino (2016), \% 0.36 ile çiçeklenme döneminde elde ettiklerini rapor etmişlerdir.

Tablo 6. Oğulotu (M. officinalis L.) bitkisinde farklı hasat dönemi ve hasat saatlerinde elde edilen uçucu yağ oranları $(\%)^{1}$

\begin{tabular}{|c|c|c|c|c|c|}
\hline \multirow{2}{*}{ Yillar } & \multirow{2}{*}{ Hasat dönemleri } & \multicolumn{3}{|c|}{ Hasat saatleri } & \multirow{2}{*}{ Ortalama } \\
\hline & & Sabah & Öğle & Akşam & \\
\hline \multirow{4}{*}{2002} & Çiçeklenme öncesi & 0.42 & 0.25 & 0.15 & 0.27 \\
\hline & $\% 50$ çiçeklenme & 0.42 & 0.42 & 0.10 & 0.31 \\
\hline & $\% 100$ çiçeklenme & 0.33 & 0.25 & 0.15 & 0.24 \\
\hline & Ortalama & $0.39 \mathrm{a}$ & $0.31 \mathrm{~b}$ & $0.13 \mathrm{c}$ & \\
\hline \multirow{4}{*}{2003} & Çiçeklenme öncesi & 0.50 & 0.25 & 0.25 & 0.33 \\
\hline & \% 50 çiçeklenme & 0.50 & 0.50 & 0.33 & 0.44 \\
\hline & $\% 100$ çiçeklenme & 0.50 & 0.33 & 0.25 & 0.36 \\
\hline & Ortalama & $0.50 \mathrm{a}$ & $0.36 \mathrm{~b}$ & $0.28 \mathrm{~b}$ & \\
\hline
\end{tabular}

$\operatorname{LSD}_{0.05} \quad \mathrm{HS}_{(2002)}=0.170^{* *}, \mathrm{HS}_{(2003)}=0.101^{* *}$

${ }^{1}$ : Konulara göre ayrı ayrı olmak üzere, aynı harfle gösterilen ortalamalar arasındaki farklılık istatistiksel olarak önemsizdir, HS: Hasat saati, **: $\mathrm{p}<0.01$ düzeyinde önemli farkl1l1k

\section{Sonuçlar}

Sonuç olarak; nane, İzmir kekiği, oğulotu ve lavanta bitkilerinde uçucu yağ oranının hasat dönemleri ve günün saatlerine göre anlamlı şekilde değişim gösterdiği belirlenmiştir. Çok farklı amaçlarla kullanılan bu bitkilerden ılıman iklimin hüküm sürdüğü Bafra-Samsun gibi ekolojik koşullarda, yüksek miktarda uçucu yağ oranı için nane ve oğulotu bitkilerinde \% 50 çiçeklenme, lavanta ve İzmir kekiği bitkilerinde ise \% 100 çiçeklenme (tam çiçeklenme) döneminde hasat edilmesinin; diurnal varyabilite bakımından ise nanede öğle, İzmir kekiği ve oğulotunda sabah, lavantada ise akşam saatlerinde hasat yapılmasının uygun olacağ1 sonucuna varılmıştır.

\section{Kaynaklar}

Alkire, B.H., Simon, J.E., 1996. Response of midwestern peppermint (Mentha piperita L.) and native spearmint (M. spicata L.) to rate and from of nitrogen fertilizer, Acta Horticulturae, 426: 537- 549.

Anonim, 2004. Samsun İli Bazı İklim Verileri. Devlet Meteoroloji Bölge Müdürlüğü Kayıtları, Samsun.

Arabac1, O., 1989. Bazı parfüm bitkilerinde (Lavandula angustifolia Mill., Mellissa officinalis L., Salvia sclarea L. ) verim ve ontogenetik varyabilite üzerine araştırmalar. Yüksek lisans tezi, Ege Üniversitesi Fen Bilimleri Enstitüsü, İzmir.

Arabac1, O., Bayram, E., 2005. Aydın ekolojik koşullarında lavanta (Lavandula angustifolia Mill.)'nın bazı agronomik ve kalite özellikleri üzerine 
bitki sıklığ1 ve azotlu gübrenin etkisi. Adnan Menderes Üniversitesi Ziraat Fakültesi Dergisi, 2(2): 13-19.

Arslan, Y., 2006. Ankara koşullarında yüksek drog ve uçucu yağ oranına sahip oğulotu (Melissa officinalis L.) hatlarının geliştirilmesi. Yüksek lisans tezi, Çukurova Üniversitesi, Fen Bilimleri Enstitüsü, Adana.

Arslancan, H., 2016. Bazı lavanta (Lavandula x intermedia Emeric ex Loisel.) ekotip ve çeșitlerinin Isparta koşullarında tarımsal ve teknolojik özelliklerinin belirlenmesi. Yüksek lisans tezi, Süleyman Demirel Üniversitesi Fen Bilimleri Enstitüsü, Isparta.

Avci, A.B., Akcali Giachino, R.R., 2016. Harvest stage effects on some yield and quality characteristics of lemon balm (Melissa officinalis L.). Industrial Crops and Products, 88: 23-27.

Balyemez, Ö.E., 2014. Harran ovası koşullarında farklı lavanta (Lavandula spp.) türlerinin verim ve bazı bitkisel özelliklerinin belirlenmesi, Yüksek lisans tezi, Harran Üniversitesi, Fen Bilimleri Enstitüsü, Şanliurfa.

Başyiğit, M., Baydar, H., 2017. Tıbbi adaçayı (Salvia officinalis L.)'nda farklı hasat zamanlarının uçucu yă ve fenolik bileşikler ile antioksidan aktivite üzerine etkisi. Süleyman Demirel Üniversitesi Fen Bilimleri Enstitüsü Dergisi, 21(1): 131-137.

Batıray, S., Kan, Y., 2013. Konya ekolojik şartlarında yetiștirilen İzmir Kekiğinde (Origanum onites L.) farklı dozlarda uygulanan azot ve organik gübrelerin verim ve kalite özellikleri üzerine etkisi. Selçuk Tartm ve Gida Bilimleri Dergisi, 27(1): 8-13.

Bayaz, M., 2014. Esansiyel yağlar: antimikrobiyal, antioksidan ve antimutajenik aktiviteleri. Akademik Glda, 12(3): 45-53.

Ceylan, A., 1997. Tıbbi Bitkiler-II (Uçucu Yağ Bitkileri). Ege Üniversitesi Ziraat Fakültesi Yayınları No: 481, İzmir.

Ceylan, A., Bayram, E., Geren, H., 1999. İzmir kekiği (Origanum onites L.) 1slahında geliştirilen klonların agronomik ve kalite özellikleri üzerinde araştırma. Türk Tarım ve Ormanclllk Dergisi, 23(Ek say1): 1163-1168.

Chang, X., Alderson, P.G., Wright, C.J., 2009. Variation in the essential oils in different leaves of basil (Ocimum basilicum L.) at day time. The Open Horticulturae Journal, 2(1): 13-16.

Court, W.A., Roy, R.C., Pocs, R., 1993. Effect of harvest date on the yield and quality of the essential oil of peppermint. Canadian Journal of Plant Science, 73: 815-824.

Çalışkan, T., Özgüven, M., 2018. Mentha arvensis var. piperascens (L.) Holmes'te ontogenetik varyabilite ve moleküler karakterizasyon. Cukurova Üniversitesi Fen ve Mühendislik Bilimleri Dergisi, 35(7): 134145.

Erdoğan, E.A., 2014. Lamiaceae familyasına ait bazı bitkilerin uçucu yağ içeriklerinin belirlenmesi, antimikrobiyal ve antimutajenik aktivitelerinin araştırılması. Doktora tezi, Mersin Üniversitesi Fen Bilimleri Enstitüsü, Mersin.

Hadiana, J., Tabatabaeia, S.M.F., Naghavib, M.R., Jamzadc, Z., Ramak-Masoumia, T., 2008. Genetic diversity of Iranian accessions of Satureja hortensis L. based on horticultural traits and RAPD markers. Scientia Horticulturae, 115(2): 196-202.

Kaçar, O., Göksu, E., Azkan, N., 2010. Oğul otu (Melissa officinalis L.) yetiştiriciliğinde farklı bitki sıklıklarının bazı tarımsal özellikler üzerine etkisi. Uludă̆ Üniversitesi Ziraat Fakültesi Dergisi, 24(2): 59-71.

Kara, N., 2011. Uçucu yağ üretimine uygun lavanta (Lavandula sp.) çeşitlerinin belirlenmesi ve mikroçoğaltım olanaklarının araştırılması. Doktora tezi, Süleyman Demirel Üniversitesi, Fen Bilimleri Enstitüsü, Isparta.

Karık, Ü., Çiçek, F., Çınar, O., 2017. Menemen ekolojik koşullarında lavanta (Lavandula spp.) tür ve çeşitlerinin morfolojik, verim ve kalite özelliklerinin belirlenmesi. ANADOLU, 27(1): 17-28.

Kızıl, S., 2009. Farklı hasat dönemlerinin oğul otu (Melissa officinalis L.)'nda bazı tarımsal özellikler üzerine etkisi. Tartm Bilimleri Dergisi, 15(1): 20-24.

Kız1l, S., Toncer, Ö., 2006. Influence of different harvest times on the yield and oil composition of spearmint (Mentha spicata L. var. spicata). Journal of Food, Agriculture \& Environment, 4(3-4): 135-137.

Kız1l, S., İpek, A., Arslan, N., Khawar, K.M., 2009. Some agronomical characteristics and essential oil content of oregano (Origanum onites L.) as influenced by planting densities. Journal of Essential Oil Bearing Plants, 12(2): 172-180.

Kokkini, S., 1992. Essential oils as taxonomic markers in Mentha. In: Advances in Labiate science, pp. 325334.

Munsi, P.S., 1992. Nitrogen and phosphorus nutrition response in Japanese mint cultivation. Acta Horticulture, Article Number 306-58: 436-443.

Özel, A., 2000. Harran Ovası koşullarında kıvırcık nane (Mentha spicata L.)'de farklı biçim zamanlarının drog verimleri ve bazı kalite kriterlerine etkisi. Harran Üniversitesi Ziraat Fakültesi Dergisi, 4(1-2): 45-56.

Özen, F., Yaldız, G., Çamlıca, M., 2017. Yabanc1 ot mücadelesinde bazı aromatik bitkilerinin uçucu yağlarının allelopatik etkisi. Uluslararası Tarım ve Yaban Hayatı Bilimleri Dergisi, 3(1): 40-48.

Özyiğit, Y., Uçar, E., Tütüncü, B., İndibi, İ., Turgut, K., 2016. The effect of different nitrogen doses on yield and some yield components of Melissa officinalis subsp. L. altissima (Sibthr. et Smith) arcang. Türkiye Tarımsal Araştırmalar Dergisi, 3(2): 139-144.

Piccaglia, R.,Dellacecca, V., Marotti, M., Giovanelli, E., Palevitch D., Putievski E., 1993. Agronomic factors affecting the yields and the essential oil composition of peppermint (Mentha piperita L.). Acta Horticulturae, Article Number 344: 29-40.

Ramakrishna, A., Ravishankar, G.A., 2011. Influence of abiotic stress signals on secondary metabolites in 
plants. Plant Signaling \& Behavior, 6(11): 17201731.

Sağlam, B., 2005. Organik gübre ile ontogenetik ve diurnal varyabilitenin Labiatae familyasına ait bazı bitkilerde (Origanum onites L., Melissa officinalis L., Thymus praceox) verim ve önemli kalite özellikleri üzerine etkisi. Yüksek lisans tezi, Ondokuz Mayıs Üniversitesi Fen Bilimleri Enstitüsü, Samsun.

Sar1, A.O., Ceylan, A., 2002. Yield characteristics and essential oil composition of lemon balm (Melissa officinalis L.) grown in the Aegean Region of Turkey. Turkish Journal of Agricultural Forestry, 26: 217224.

Shanjani, P.S., Mirza, M., Calagari, M., Adams, R.P., 2010. Effects drying and harvest season on the essential oil composition from foliage and berries of Juniperus excelsa. Industrial Crops and Products, 32(2): 83-87.

Sönmez, Ç., 2019. Effect of different harvest times on some yield and essential oil characteristics in Origanum onites L.. Turkish Journal Of Field Crops, 24(1):106-110.

Sönmez, Ç., Okkaoğlu, H., 2019. The effect of diurnal variation on some yield and quality characteristics of lavender (Lavandula angustifolia Mill.) under Çukurova ecological conditions. Turkish Journal of Agriculture-Food Science and Technology, 7(3): 531535.

Stevovic, S., Calic-Dragosavac, D., Mikovilovic, V.S., Zdravkovic-Korac, S., Milojevic, J., Cingel, A., 2011. Correlation between environment and essential oil production in medicinal plants. Advances in Environmental Biology, 5(2): 465-468.

Şengül, Z., 1990. Nanede verim ve ontogenetik varyabilite üzerine araştırmalar. Yüksek lisans tezi, Ege Üniversitesi Fen Bilimleri Enstitüsü, İzmir.

Telci, I., Demirtas, I., Bayram, E., Arabaci, O., Kacar, O., 2010. Environmental variation on aroma components of pulegone/piperitone rich spearmint (Mentha spicata L.). Industrial Crops and Products, 32: 588592.

Telli, H., 2007. Seçilmiş oğulotu (Melissa officinalis L.) hatlarının drog verimi ve uçucu yağ oranı bakımından karșılaștırılması. Yüksek lisans tezi, Ankara Üniversitesi Fen Bilimleri Enstitüsü, Ankara.

Tınmaz, A.B., 1999. Oğul otu (Melissa officinalis L.) bitkisinin uygun dikim sıklığ1 ve hasat zamanının belirlenmesi. Yüksek lisans tezi, Onsekiz Mart Üniversitesi Fen Bilimleri Enstitüsü, Çanakkale.

Tuğay, M.E., Kaya, N., Yılmaz, G., Telci, I., Dönmez, E., 2000. Tokat ve çevresinde yaygın olarak bulunan bazı aromatik bitkilerin bitkisel ve teknolojik özellikleri. TÜBİTAK, Tarım ve Ormancılık Araştırma Grubu, Proje Kesin Sonuç Raporu (TOGTAG-1690).

Uçar, E., Odabaş Köse, E., Özyiğit, Y., Turgut, K., 2015. Bazı tıbbi ve aromatik bitkilerde esansiyel yağların antimikrobiyal aktivitelerinin belirlenmesi. Süleyman Demirel Üniversitesi Ziraat Fakültesi Dergisi, 10(2): 118-124.

Ulcay, S., Şenel, G., 2018. Lamiaceae familyasına ait Lycopus europaeus L. türü üzerinde anatomik bir araştırma. Sinop Üniversitesi Fen Bilimleri Dergisi, 3(1): 45-52.

Uyanık, M., 2013. Oğulotu (Melissa officinalis L.)'nda ontogenetik, morfogenetik ve diurnal varyabilitenin Ankara koşullarında belirlenmesi. Yüksek lisans tezi, Ankara Üniversitesi Fen Bilimleri Enstitüsü, Ankara.

Yaldiz, G., Sekeroğlu, N., Özgüven, M., Kirpik, M., 2005. Seasonal and diurnal variability of essential oil and its components in Origanum onites L. grown in the ecological conditions of Çukurova. Grasas y Aceites, 56(4): 254-258.

Yurtsever, N., 1984. Deneysel İstatistik Metotları. Toprak ve Gübre Enstitüsü Yayınları, Genel Yayın No: 121, Ankara.

Zheljazkov, V.D., Astatkie, T., Hristov, A.N., 2012. Lavender and hyssop productivity, oil content, and bioactivity as a function of harvest time and drying. Industrial Crops and Products, 36: 222-228. 